ARTICLE

Received 6 Jun 2014 | Accepted 16 Jan 2015 | Published 18 Feb $2015 \quad$ DOI: 10.1038/ncomms7305

\title{
Considerably improved photovoltaic performance of carbon nanotube-based solar cells using metal oxide layers
}

Feijiu Wang ${ }^{1}$, Daichi Kozawa', Yuhei Miyauchi'1,2, Kazushi Hiraoka ${ }^{3}$, Shinichiro Mouri ${ }^{1}$, Yutaka Ohno ${ }^{4}$ \& Kazunari Matsuda ${ }^{1}$

Carbon nanotube-based solar cells have been extensively studied from the perspective of potential application. Here we demonstrated a significant improvement of the carbon nanotube solar cells by the use of metal oxide layers for efficient carrier transport. The metal oxides also serve as an antireflection layer and an efficient carrier dopant, leading to a reduction in the loss of the incident solar light and an increase in the photocurrent, respectively. As a consequence, the photovoltaic performance of both $p$-single-walled carbon nanotube (SWNT)/n-Si and $n$-SWNT/p-Si heterojunction solar cells using $\mathrm{MoO}_{x}$ and $\mathrm{ZnO}$ layers is improved, resulting in very high photovoltaic conversion efficiencies of 17.0 and $4.0 \%$, respectively. These findings regarding the use of metal oxides as multifunctional layers suggest that metal oxide layers could improve the performance of various electronic devices based on carbon nanotubes.

\footnotetext{
${ }^{1}$ Institute of Advanced Energy, Kyoto University, Uji 611-0011, Japan. ${ }^{2}$ Japan Science and Technology Agency, PRESTO, Kawaguchi 332-0012, Japan. ${ }^{3}$ Hitachi Zosen Corporation, Taisho 551-0022, Japan. ${ }^{4}$ Department of Quantum Engineering, Nagoya University, Chikusa-ku, Nagoya 464-8603, Japan. Correspondence and requests for materials should be addressed to K.M. (email: matsuda@iae.kyoto-u.ac.jp).
} 
ver the past decade, photovoltaic devices using nanoscale materials, such as semiconductor quantum dots ${ }^{1-3}$, nanowires $^{4-6}$ and so on $^{7}$, have been extensively studied. Carbon nanotubes with cylinder-like, one-dimensional structures have attracted much interest for photovoltaic applications because of their electronic and optical properties ${ }^{8-11}$, including the ability to tune their band gaps over a wide wavelength range ${ }^{12}$, high carrier mobilities along their one-dimensional axes $^{13,14}$ and high optical transparency values with low resistivity ${ }^{15}$. Indeed, a variety of photovoltaic devices using carbon nanotubes such as carbon nanotube-based organic solar cells $^{16}$, photoelectrochemical cells ${ }^{17}$, dye-sensitized solar cells ${ }^{18}$ and carbon nanotube/Si solar cells ${ }^{19,20}$ have been reported. Furthermore, the importance of carbon nanotubes as photovoltaic materials is continually increasing.

However, several crucial issues remain to be solved for further improvement of the carbon nanotube photovoltaic device performance and to enable the shift from the fundamental research to the technological applications development. First, a high Schottky barrier at the interface of the carbon nanotubes and the metal electrode limits the performance in carbon nanotubebased photovoltaic devices. Control of the Schottky barrier using an efficient carrier transport layer should enable the delivery of a high current without the carrier recombination loss ${ }^{21}$. Second, more efficient carrier doping for the carbon nanotubes is required to reduce the series resistance loss and increase the power conversion efficiency. Third, solar light management within the device structure of the carbon nanotube solar cells is required to enhance the photocarrier generation efficiency.

In this paper, we report on the improvement in the photovoltaic performance of the carbon nanotube-based solar cells containing environmentally friendly, durable and inexpensive $\mathrm{MoO}_{x}$ and $\mathrm{ZnO}$ metal oxide layers. The $\mathrm{MoO}_{x}$ and $\mathrm{ZnO}$ layers play multiple roles as antireflection, carrier doping and efficient carrier transport layers in the carbon nanotube-based solar cells. The photovoltaic performance of the single-walled carbon nanotube (SWNT)/Si hybrid solar cells is improved using these multifunctional $\mathrm{MoO}_{x}$ and $\mathrm{ZnO}$ layers, with high power conversion efficiencies (PCE) of 17.0 and $4.0 \%$ achieved for $p$-SWNT/n-Si and $n$-SWNT/p-Si devices, respectively. The $17.0 \%$ PCE value is the highest yet reported for the PCE of $p$-SWNT and the $4.0 \%$ PCE value is also quite high compared to the $n$-SWNT hybrid solar cells reported in the literature. The detailed physical mechanism of the multifunctional layers is also discussed.

\section{Results}

Structure of the solar cells. Figure $1 \mathrm{a}, \mathrm{b}$ shows schematics of the $p$-SWNT/ $n$-Si heterojunction solar cells without and with an $\mathrm{MoO}_{x}$ layer, respectively. To fabricate the $p$-SWNT $/ n$-Si heterojunction solar cells with the $\mathrm{MoO}_{x}$ layer, the $\mathrm{MoO}_{x}$ layer is evaporated on the SWNT network film, and then a gold ( $\mathrm{Au}$ ) contact is coated using the mask of the active window area. The $\mathrm{MoO}_{x}$ layer consists of two parts; one section of the $\mathrm{MoO}_{x}$ layer is sandwiched by the SWNT film and the Au contact, and the other one is only in contact with the SWNT film in the window area of the solar cell.

Figure 1c,d shows the scanning electron microscope (SEM) images of the SWNT network film without and with the $\mathrm{MoO}_{x}$ coating. The average diameter of the SWNTs is determined to be $1.6 \mathrm{~nm}$ from the absorption spectrum of the film (Supplementary Fig. 1$)^{22}$. The SWNT film without the $\mathrm{MoO}_{x}$ coating exhibits a spider web-like structure consisting of the interconnected nanotube bundles with the diameters ranging from several to tens of nanometres. The evaporation of $\mathrm{MoO}_{x}$ for $60 \mathrm{~s}$ results in the SWNT network film being covered by a very thin $\mathrm{MoO}_{x}$ layer.
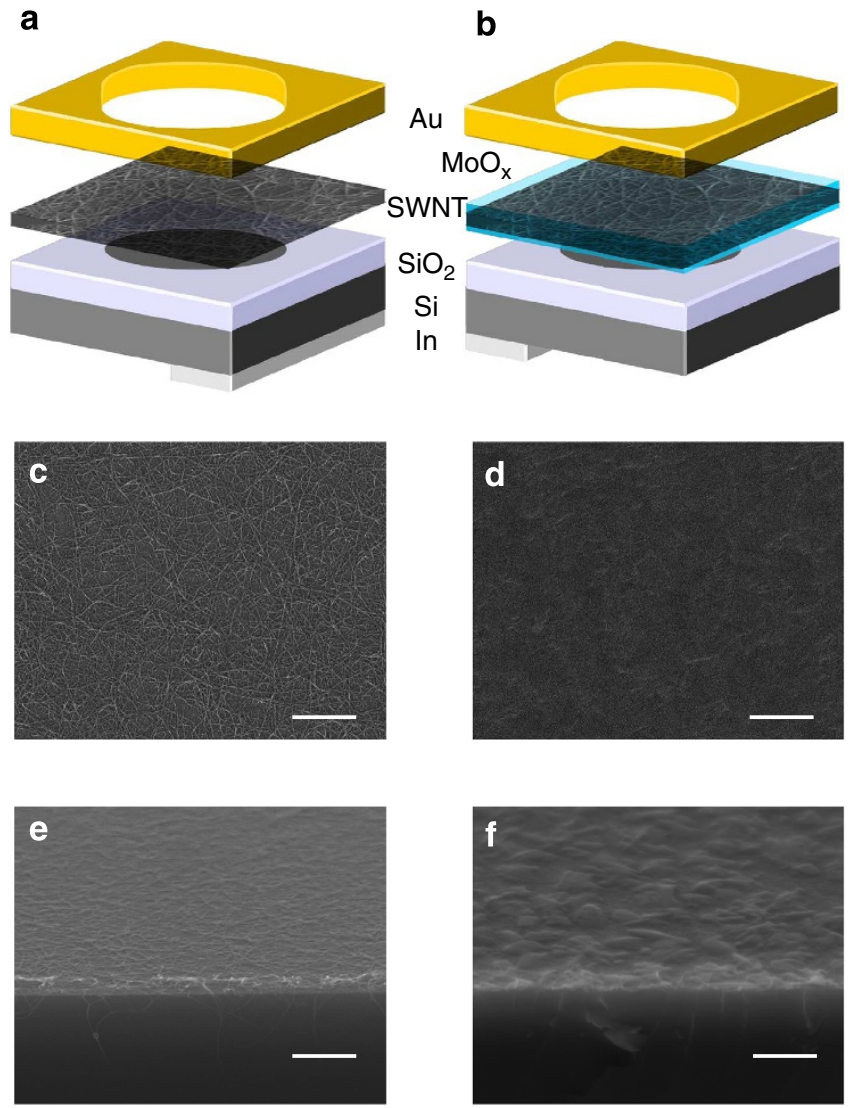

Figure 1 | Schematics of the solar cell devices and characterization of the SWNT network film. (a,b) Schematics of the pristine-SWNT/Si and

$\mathrm{MoO}_{x}-\mathrm{SWNT} / \mathrm{Si}$ solar cells, respectively. (c,d) Top-view SEM images of the SWNT network film on an Si wafer and the SWNT film with an $\mathrm{MoO}_{x}$ layer, respectively. $(\mathbf{e}, \mathbf{f})$ Cross-sectional SEM images of the pristine-SWNT/Si and $\mathrm{MoO}_{x}-\mathrm{SWNT} / \mathrm{Si}$ solar cells, respectively. Scale bar in each figure is $1 \mu \mathrm{m}$.

Figure 1e,f show cross-sectional views of the SWNT/Si layers, which are used to determine the thickness of the $\mathrm{MoO}_{x}$ layer. A textured surface structure is observed for the SWNT/Si with the $\mathrm{MoO}_{x}$ layer (Fig. 1f), and the average thickness of the $\mathrm{MoO}_{x}$ layer was determined to be $\sim 40 \mathrm{~nm}$. Notably, as the deposition time increased, the $\mathrm{MoO}_{x}$ layer on the SWNT film becomes flat. SEM images of SWNT films coated with thicker $\mathrm{MoO}_{x}$ layers are shown in Supplementary Fig. 2.

Performance of carbon nanotube solar cells with $\mathrm{MoO}_{x}$ layers. The current density-voltage $(J-V)$ characteristics of the $p$-SWNT/ $n$-Si solar cells under the air mass (AM) 1.5 conditions are shown in Fig. 2a. Typical photovoltaic behaviour is observed; the $J-V$ curve of the pristine-SWNT/Si solar cell (black solid line) exhibits a short-circuit current density $\left(J_{\mathrm{sc}}\right)$ of $27.9 \mathrm{~mA} \mathrm{~cm}^{-2}$, an opencircuit voltage $\left(V_{\mathrm{oc}}\right)$ of $0.57 \mathrm{~V}$ and a fill factor $(\mathrm{FF})$ of $69 \%$, resulting in a PCE $(\eta)$ of $11.1 \%$. In contrast, the $J-V$ curve for the solar cell containing the $\mathrm{MoO}_{x}$-coated SWNT film $\left(\mathrm{MoO}_{x^{-}}\right.$ SWNT/Si) exhibits a very high $J_{\mathrm{sc}}$ value of $36.6 \mathrm{~mA} \mathrm{~cm}^{-2}$, which is close to the maximum value reported for Si solar cells ${ }^{23}$ and is the highest short-circuit current density for hybrid solar cells using crystalline $\mathrm{Si}$ and other nanomaterials. This short-circuit current density value is associated with a $V_{\text {oc }}$ of $0.59 \mathrm{~V}$ and an FF of $78 \%$, resulting in a very high $17.0 \% \eta$ value that represents a $50 \%$ increase in the PCE compared with that of the pristineSWNT/Si solar cell. It should be noted that the thickness of the $\mathrm{MoO}_{x}$ layer $(\sim 40 \mathrm{~nm})$ is optimized for the $\mathrm{MoO}_{x}-\mathrm{SWNT} / \mathrm{Si}$ solar 
a

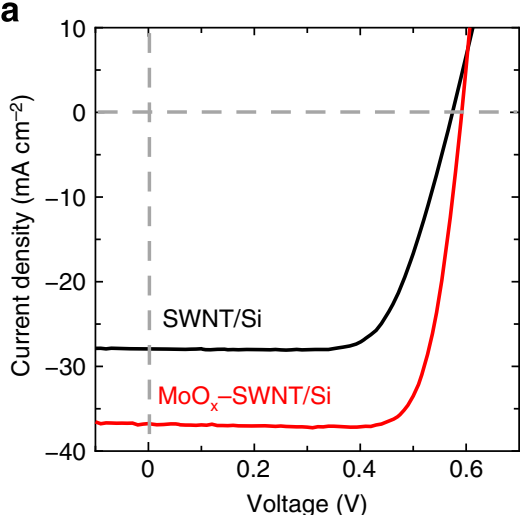

C

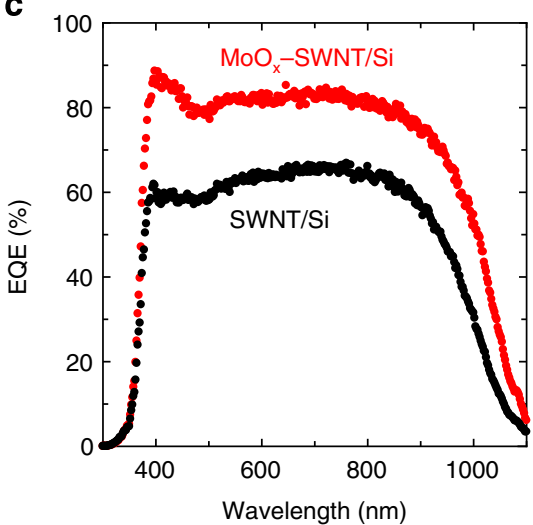

b
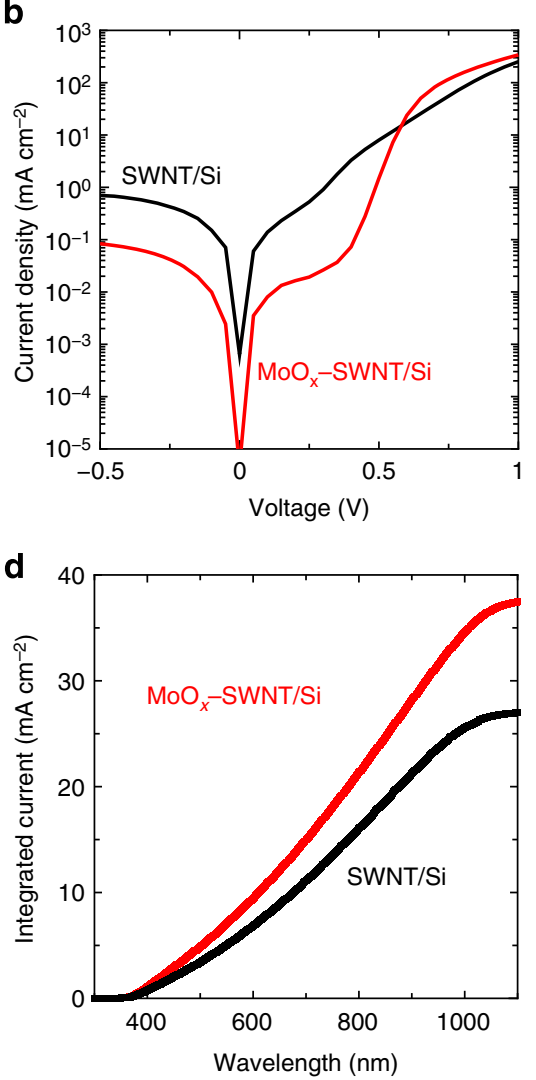

Figure 2 | Photovoltaic properties of the solar cell devices. (a) J-V curves for an SWNT/Si solar cell recorded under AM 1.5G (solid lines) and dark (dashed lines) conditions before (black lines) and after (red lines) the vapour deposition of an $\mathrm{MoO}_{x}$ layer. (b) Log-plot of the dark current before (black line) and after (red line) the deposition of the $\mathrm{MoO}_{x}$ coating. (c) IPCE spectra before (black line) and after (red line) the deposition of the MoO $x$ coating. (d) Calculated integrated photocurrent under AM 1.5G irradiation before (black line) and after (red line) the deposition of the MoO $\mathrm{O}_{x}$ coating.

cell (Supplementary Figs 3 and 4). This very high $\eta$ of $17.0 \%$ is the highest value reported to date for the carbon-based solar cells, including the SWNT/Si solar cells. Furthermore, the $J-V$ curves for the $p$-SWNT $/ n$-Si solar cells in Fig. $2 \mathrm{a}$ are well reproduced by the fitted curves (Supplementary Fig. 5) calculated using the equivalent circuit model (details are shown in Supplementary Note 1 and Supplementary Fig. 11). The values of the shunt resistance, series resistance and diode ideality factor are much improved for the $\mathrm{MoO}_{x}$-SWNT/Si solar cell and are shown in the Supplementary Table 1 . We also investigated the PCE variations among five solar cells fabricated with the optimized device parameters. A very small variation of the PCE in the 15.8-17.6\% range is observed as shown in the Supplementary Table 2.

The $J-V$ characteristics for both the pristine-SWNT/Si and $\mathrm{MoO}_{x}-\mathrm{SWNT} / \mathrm{Si}$ solar cells clearly exhibit the diode properties. However, the $\mathrm{MoO}_{x}$-SWNT/Si solar cell showed much better diode properties with a lower reverse leakage current and three orders of magnitude higher rectification ratio compared with those of the pristine-SWNT/Si solar cell. This suggests a reduction of the series resistance and an increase in the shunt resistance with the addition of the $\mathrm{MoO}_{x}$ coating in the SWNT/Si solar cell. An increase in the dark current under forward bias conditions above $0.5 \mathrm{~V}$ is also observed. This result indicates that the hole extraction efficiency is improved because of the $\mathrm{MoO}_{x}$ coating $^{24,25}$, which will be discussed below. Moreover, the diode ideality factor $n(=1.08)$ for the $\mathrm{MoO}_{x}-\mathrm{SWNT} / \mathrm{Si}$ solar cell is lower than that of the pristine-SWNT/Si $(=1.24)$. Such a low value for the diode ideality factor is an indication of the efficient transport characteristics with minimum interfacial recombination in the $\mathrm{MoO}_{x}$-SWNT/Si solar cell.
Next, the effects of the $\mathrm{MoO}_{x}$ coating incorporation in the SWNT/Si solar cell are further investigated to understand the improvement in the photovoltaic properties. Figure $2 c$ presents the spectra of the incident photon-to-current efficiency (IPCE) for the pristine-SWNT/Si and the $\mathrm{MoO}_{x}-\mathrm{SWNT} / \mathrm{Si}$ solar cells. A broad and flat value of $\sim 65 \%$ in the spectrum of the original pristine-SWNT/Si cell is observed from 400 to $900 \mathrm{~nm}$, which corresponds to the wavelength range of Si light absorption and suggests that the $\mathrm{Si}$ substrate plays a role in the solar light absorption and photocarrier generation of the cell ${ }^{26,27}$, while the SWNT mainly works as the efficient carrier separation, collection and transport layer ${ }^{27}$. In contrast, the IPCE spectrum of the $\mathrm{MoO}_{x}-\mathrm{SWNT} / \mathrm{Si}$ solar cell exhibits a large increase in the external quantum efficiency (EQE) and surpassed $80 \%$ for the wavelengths between 400 and $900 \mathrm{~nm}$. Figure $2 \mathrm{~d}$ shows the integrated currents calculated using the overlap between the EQE spectrum and the AM 1.5G solar photon flux for each cell. The calculated integrated photocurrent yields current densities of 27 and $36.5 \mathrm{~mA} \mathrm{~cm}^{-2}$ for the pristine-SWNT/Si and $\mathrm{MoO}_{x}-\mathrm{SWNT} / \mathrm{Si}$ solar cells, respectively. Notably, these results are consistent with the photocurrent densities determined from the $J-V$ curves, as shown in Fig. 2a.

Roles of $\mathrm{MoO}_{x}$ layer in SWNT/Si solar cells. Thus, a dramatic improvement in the photovoltaic performance of the SWNT/Si solar cell due to the inclusion of an $\mathrm{MoO}_{x}$-coated SWNT film is demonstrated. The $\mathrm{MoO}_{x}$ layer inserted between the SWNT film and the $\mathrm{Au}$ anode serves as an effective hole transporting layer. Moreover, the $\mathrm{MoO}_{x}$ layer on the SWNT network film in the 
active window functions as an antireflection layer for the solar light and as a carrier dopant for the SWNTs. A detailed analysis of the physical mechanisms involved in the improved photovoltaic performance of the $\mathrm{MoO}_{x}$-coated SWNT film is presented below.

Some materials inserted between the semiconducting hole generation layers and the anodes can increase the hole extraction/ injection efficiency for optoelectronic devices through the reduction of the Schottky barrier at the interface. The semiconducting SWNT film with a diameter of $1.6 \mathrm{~nm}$ has a bandgap of about $0.9 \mathrm{eV}$ when the exciton binding energy is taken into account ${ }^{28}$. The work function of the SWNTs is determined to be $4.7 \mathrm{eV}$ (ref. 29). Because of the difference in the work functions of the SWNTs and $\mathrm{Au}(5.3 \mathrm{eV})^{30}$, an interface dipole layer is formed at the SWNT/Au-anode interface until the valence band edge of the SWNTs aligns with the Fermi level of the Au anode; this is accompanied by large band bending, as shown in Fig. 3a. Such a pinning effect involved in the alignment of the valence band edge and the Fermi level has been observed using scanning tunnelling spectroscopy ${ }^{30}$. The presence of the $\mathrm{MoO}_{x}$ coating and the interaction between the $\mathrm{MoO}_{x}$ layer and the SWNT film leads to significant changes in the electronic structure of the SWNT surface and the consequent modification of the surface potential. The work function of the $\mathrm{MoO}_{x}$ layer is higher than the ionization energy of the SWNTs and is close to the Fermi level of the SWNTs; this enables efficient hole transfer from the SWNTs to the $\mathrm{Au}$ anode via the $\mathrm{MoO}_{x}$ layer. $\mathrm{MoO}_{x}$ films have been frequently observed to function as hole transport layers in organic semiconductor/Au interfaces ${ }^{31}$. The change in the band alignment due to the insertion of the $\mathrm{MoO}_{x}$ layer promotes photocarrier extraction from the SWNTs to the $\mathrm{Au}$ anode, leading to a significant increase in the short-circuit current density and a reduction of the net series resistance $\left(R_{\mathrm{s}}\right)$ value. Therefore, as an effective hole transport layer, $\mathrm{MoO}_{x}$ enhances the photovoltaic performance by preventing current leakage and consequent counter-diode formation ${ }^{32}$, as is also illustrated in Fig. 2b.

To reveal the role of the $\mathrm{MoO}_{x}$ film as a hole transport layer, a $p$-SWNT/ $n$-Si solar cell with an $\mathrm{MoO}_{x}$ layer between the SWNT film and the Au anode is fabricated (Supplementary Fig. 6). The $\eta$ value of $14.2 \%$ for the $p$-SWNT/ $n$-Si solar cell with the $\mathrm{MoO}_{x}$ coating on the active area is much enhanced compared with $\eta=11.5 \%$ obtained for the pristine-SWNTs/Si solar cell. On the basis of this result, it is concluded that the PCE value increases because the $\mathrm{MoO}_{x}$ layer acts mainly as a hole extraction layer and reduces the Schottky barrier height at the interface between the SWNT film and the $\mathrm{Au}$ anode.

Next the reflectance spectra of the pristine-SWNT/Si and $\mathrm{MoO}_{x}$-SWNT/Si solar cells are obtained to evaluate the ability of the $\mathrm{MoO}_{x}$ layer to act as the antireflection layer, as shown in Fig. 3c. The reflectivity $(R)$ of the pristine-SWNT/Si solar cell is $\sim 30 \%$, mainly because of the high refractive index of $\mathrm{Si}$ for wavelength between 400 and $1,000 \mathrm{~nm}$. On the other hand, the reflectivity of the $\mathrm{MoO}_{x}-\mathrm{SWNT} / \mathrm{Si}$ solar cell is substantially lower over the entire spectral region from 300 to $1,100 \mathrm{~nm}(<20 \%)$. This decrease in the reflectivity contributes to the increase in the

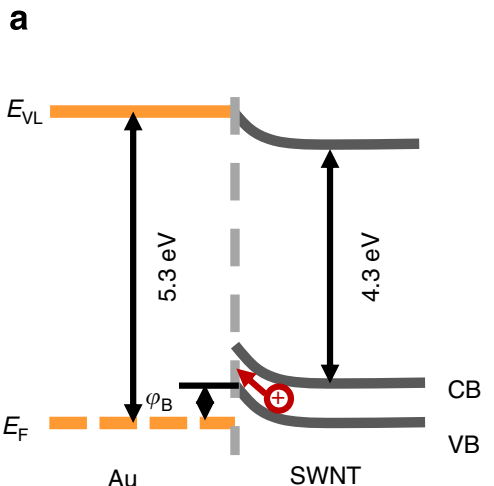

C

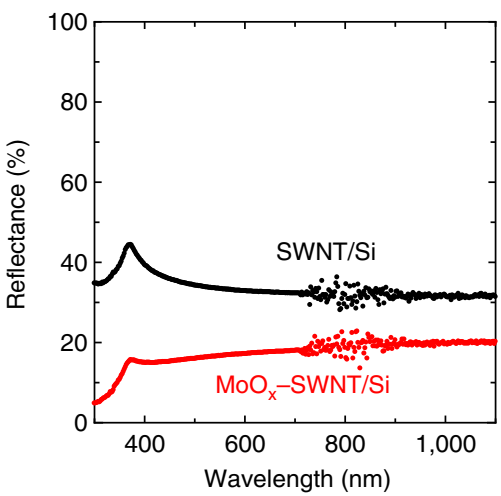

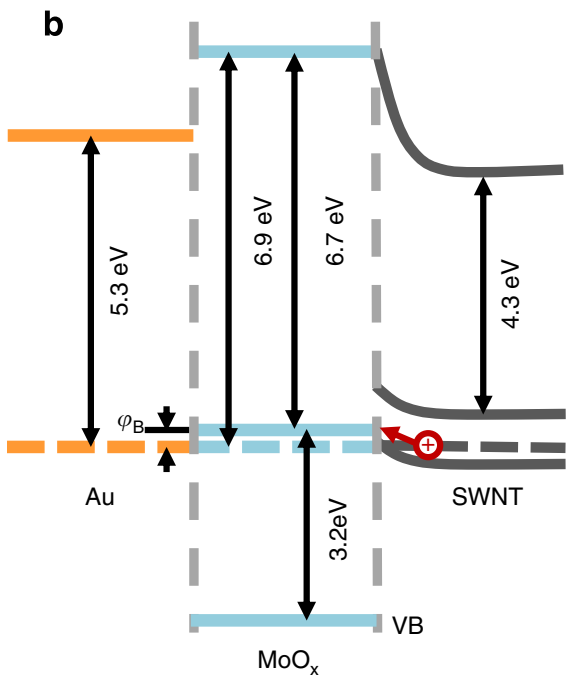

d

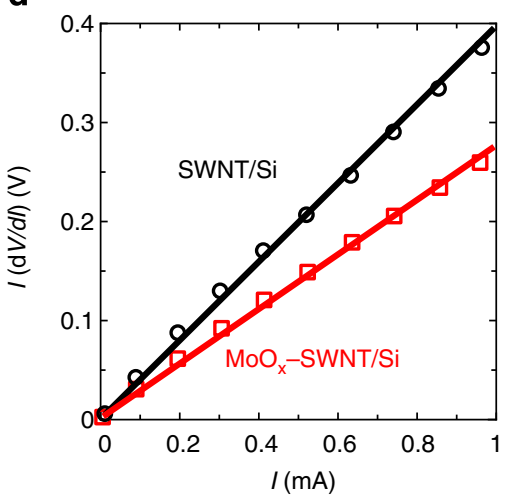

Figure 3 | Multifunctional performance of $\mathbf{M o O}_{\boldsymbol{x}}$ layer. $(\mathbf{a}, \mathbf{b})$ Bandgap alignments of the pristine-SWNT/Au and the MoO $\mathrm{O}_{x}-\mathrm{SWNT} / \mathrm{Au}$ interfaces, respectively. (c) Reflectance spectra of the pristine-SWNT/Si (black line) and $\mathrm{MoO}_{x}-\mathrm{SWNT/Si}$ (solid line) solar cells. (d) I(dV/d/) plots of the pristineSWNT/Si (black line) and $\mathrm{MoO}_{x}-\mathrm{SWNT} / \mathrm{Si}$ (red line) solar cells as a function of the current $I$. 
solar light absorption and the generation of the photocarriers in the Si substrate, resulting in an enhancement of the short-circuit current density. This assumption is confirmed by the evaluation of the internal quantum efficiency (IQE) using the relationship $\mathrm{IQE}=\mathrm{EQE} /(1-R)($ Supplementary Note 2$)$. The calculated IQE spectrum of the $\mathrm{MoO}_{x}-\mathrm{SWNT} / \mathrm{Si}$ solar cell is nearly coincident with that of the pristine-SWNT/Si, which strongly suggests that a reduction in the reflectivity contributes to the increased $\mathrm{EQE}$ in the $\mathrm{MoO}_{x}-\mathrm{SWNT} / \mathrm{Si}$ solar cell (Supplementary Fig. 8). The $\mathrm{MoO}_{x}$ layer reduced the effective refractive index mismatch between $\mathrm{Si}$ and air, because $\mathrm{MoO}_{x}$ has an intermediate refractive index $\left(n_{0}=2.2\right)^{33}$. This decrease in the reflectivity of the $\mathrm{MoO}_{x}$-SWNT/Si solar cell reduced the loss of solar light and increased photocarrier generation and was due to the fact that the $\mathrm{MoO}_{x}$ layer acts as an antireflection layer.

The $\mathrm{MoO}_{x}$ also plays a role as a carrier dopant for the SWNTs. Figure $3 \mathrm{~d}$ shows the $I(\mathrm{~d} V / \mathrm{d} I)$ plots for the pristine-SWNT/Si and $\mathrm{MoO}_{x}-\mathrm{SWNT} / \mathrm{Si}$ solar cells as a function of the current $(I)$. The $R_{\mathrm{s}}$ of the solar cells without and with the $\mathrm{MoO}_{x}$ coating is evaluated from the slope of this plot, and the resistance of the $\mathrm{MoO}_{x}-\mathrm{SWNT} / \mathrm{Si}$ solar cell $(=244 \Omega)$ is found to be significantly lower than that of the pristine-SWNT/Si $(=360 \Omega)$. The decrease of the $R_{\mathrm{s}}$ is also confirmed by the independent two-probe method (Supplementary Fig. 10, Supplementary Table 3 and Supplementary Note 3). Hole doping for the SWNTs in the $\mathrm{MoO}_{x}$-SWNT occurs because the ionization energy of SWNTs is lower than the work function of the $\mathrm{MoO}_{x}$ layer, and thus the series resistance decreased ${ }^{34}$. We also confirm the effect of hole doping for SWNTs by the $\mathrm{MoO}_{\mathrm{x}}$ layer using Raman spectra (Supplementary Fig. 9), which are similar to the previously reported results ${ }^{34}$. Therefore, an SWNT/Si solar cell with an $\mathrm{MoO}_{x}$ layer only on the active window (Supplementary Fig. 7) was fabricated to evaluate the antireflection layer and hole doping effects of the $\mathrm{MoO}_{x}$ layer. On the basis of the $J-V$ curves obtained for this $\mathrm{MoO}_{x}$-SWNT/Si solar cell, the value of $J_{\mathrm{sc}}$ is found to be increased by $\sim 6.5 \mathrm{~mA} \mathrm{~cm}^{-2}$ in the $\mathrm{MoO}_{x}$-SWNT/Si solar cell compared with that of the cell without the metal oxide layer. Furthermore, in the IQE spectra, an increase in the IQE is also observed for the cell with the $\mathrm{MoO}_{x}$ layer, indicating the effective hole doping achieved by the addition of the $\mathrm{MoO}_{x}$ coating.

We quantitatively evaluated the contribution of the $\mathrm{MoO}_{x}$ coating to the PCE increase (Supplementary Note 4). The possibility of surface passivation by the $\mathrm{MoO}_{x}$ coating was also checked (Supplementary Fig. 12) ${ }^{35,36}$. However, we could not observe these effects. The increased PCE by the $\mathrm{MoO}_{x}$ coating is estimated to arise from the changes in the series resistance, shunt resistance and diode loss from the equivalent circuit model ${ }^{26,37}$, and the reflection loss of solar light. The series resistance including the components of the SWNT film sheet resistance and the contact resistance for the SWNT/Au interface drastically decreases from $360(2.83)$ to $117 \Omega\left(0.92 \Omega \mathrm{cm}^{2}\right)$, resulting in the PCE improvement of $2.08 \%$. Further, PCE increase of 1.46 and $0.09 \%$ are due to the reduction of recombination loss and diode loss, respectively, resulted due to an increase in the shunt resistance. Moreover, the estimated reduction of the reflected solar light by the antireflection effect increase the current density by $5.9 \mathrm{~mA} \mathrm{~cm}^{-2}$ (Supplementary Note 2), resulting in the PCE improvement of $2.25 \%$. The evaluated total increase of $5.9 \%$ is good agreement with the experimentally observed PCE improvement due to the $\mathrm{MoO}_{x}$ coating, as shown in Fig. 2a. These quantitative results strongly support the hypothesis that the $\mathrm{MoO}_{x}$ acts as a dopant and hole transporting layer, and as an antireflection layer, drastically improving the photovoltaic performance of the SWNT/Si solar cells. A statistic distribution of photovoltaic characteristics is shown in Supplementary Fig. 13. The high value of conversion efficiencies and small distribution of
SWNT/MoO $/$ Si solar cells show a high reproducibility of the photovoltaic devices.

$n$-SWNT/p-Si solar cells with ZnO layer. Finally, to determine if a similar improvement in photovoltaic performance could be achieved for a cell based on the $n$-type carbon nanotubes, similar experiments were performed using an $n$-SWNT/p-Si solar cell with $\mathrm{ZnO}$ insertion layers. In this study, $n$-SWNT/p-Si solar cells with and without a $\mathrm{ZnO}$ layer between the SWNT network film and the electrode were fabricated. Details of the fabrication procedure are provided in the Supplementary Note 5 and the morphology of the $\mathrm{ZnO}$ layer is shown in Supplementary Fig. 15. Figure 4 shows the $J-V$ characteristics of the $n$-SWNT/p-Si (solid black line) and ZnO-SWNT/Si (red solid line). Even for the $n$-SWNT/p-Si cell without the ZnO layer, the PCE determined from the $J-V$ curve is $1.3 \%$. Moreover, a drastic increase in the PCE to $4.0 \%$ is observed for the $\mathrm{ZnO}-\mathrm{SWNT} / \mathrm{Si}$ cell (Supplementary Table 4). The enhancement of the PCE resulted from an increase in the short-circuit current density and FF in the $n$-SWNT/p-Si solar cell fabricated with the ZnO-coated SWNT film. The increased short-circuit current density results from a reduction in the loss of the solar light reflectance, an efficient extraction of the electrons to the contact and a decrease in the series resistance of the SWNTs. Moreover, the FF increases because of a reduction in the series resistance with the increase in the carrier doping (Supplementary Fig. 14). These results indicated that similar to $\mathrm{MoO}_{x}$, the $\mathrm{ZnO}$ layer plays several roles, acting as an antireflection layer, a carrier dopant and an electron transport layer and leads to a drastic improvement in the photovoltaic performance of the $n$-SWNT/p-Si solar cells.

In conclusion, we investigated the photovoltaic performance of the carbon nanotube-based solar cells using environmentally friendly, durable and inexpensive materials such as $\mathrm{MoO}_{x}$ and $\mathrm{ZnO}$ that act as the antireflection layers for the increased optical absorption, carrier dopants for the reduction of the series resistance and effective carrier transport layers for the reduction of the Schottky barrier. The photovoltaic performance of the $p$-SWNT/n-Si and $n$-SWNT/p-Si heterojunction solar cells was improved using multifunctional layers of $\mathrm{MoO}_{x}$ and $\mathrm{ZnO}$, resulting in very high PCE values of 17.0 and $4.0 \%$, respectively. We expect that metal oxides such as $\mathrm{MoO}_{x}$ and $\mathrm{ZnO}$ will contribute to the improvement of the device performance not only for photovoltaics but also for other optoelectronics.

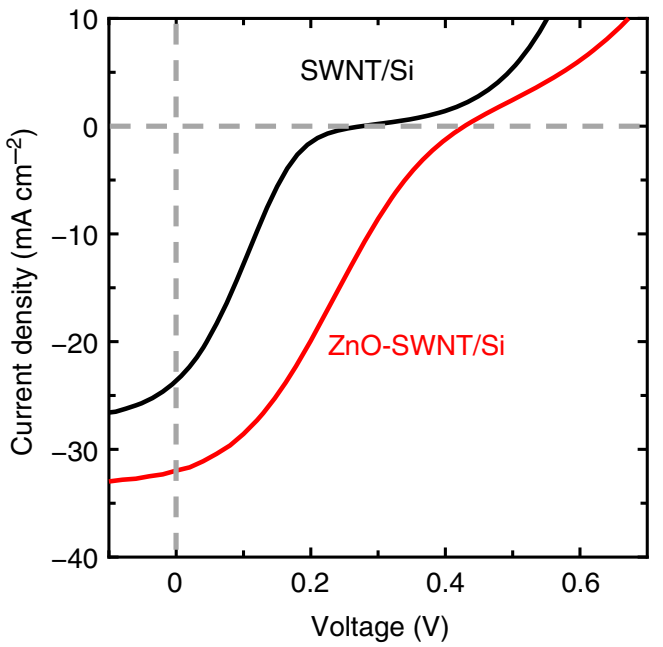

Figure 4 | Photovoltaic performance of $\boldsymbol{n}$-SWNT/p-Si solar cells. $J-V$ curves for the $n-S W N T / p$-Si solar cells without (black line) and with (red line) a $\mathrm{ZnO}$ layer. 
Our finding also reveals new aspects of the device physics and the potential for optoelectronic applications based on the carbon nanotubes.

\section{Methods}

Fabrication of the SWNT network films. SWNTs were grown using the floating catalyst chemical vapour deposition method ${ }^{22,38,39}$. Carbon monoxide (CO) was used as the carbon source, and the catalyst particles were produced via the decomposition of the ferrocene vapour. CO (100 s.c.c.m.) was passed through a temperature-controlled cartridge containing the ferrocene powder. Additional $\mathrm{CO}$ $(300 \mathrm{sccm})$ and $\mathrm{CO}_{2}$ (3 s.c.c.m.) were also introduced to the furnace, and the growth temperature was set at $850^{\circ} \mathrm{C}$. The SWNT film was collected at room temperature on a membrane filter comprising cellulose acetate and nitrocellulose. The thickness of the SWNT film was controlled by varying the collection time.

Device fabrication. An $n$-Si substrate $(1-10 \Omega \mathrm{cm})$ was used for the solar cell devices. The native $\mathrm{SiO}_{2}$ layer of the active window was removed using a buffered HF solution. The membrane filter with the SWNT network film was then placed on the Si substrate such that the SWNT network film was in direct contact with the top surface of the substrate. A fibre wiper was then applied to the surface of the substrate with adequate pressure to release the film from the membrane filter and create a connection between the film and the substrate. It was essential to place a drop of ethanol on the surface to ensure good contact between the film and the substrate and to densify the SWNT film ${ }^{17}$. The $\mathrm{MoO}_{x}$ films were deposited via thermal evaporation of $\mathrm{MoO}_{3}$ at a rate of $0.5 \mathrm{~nm} \mathrm{~s}^{-1}$ and base pressure of $5 \times 10^{-6}$ Torr. SWNT films with window sizes ( $\phi$ : diameter) of $1.0 \mathrm{~mm}$ were used. Each SWNT film was then connected to the Au anode, while each $n$-Si substrate was connected to an indium (In) cathode.

Characterization and measurements. The optical absorption and reflectance spectra of the SWNT network films were obtained using a UV/Vis/NIR spectrophotometer (Hitachi U-4100). To perform the photovoltaic testing, the devices were irradiated using a solar simulator (San-Ei Electric XES-40S1) at AM 1.5 $\left(\sim 100 \mathrm{~mW} \mathrm{~cm}^{-2}\right)$, and the current density-voltage data were recorded using a source meter (Keithley 2400). The AM 1.5 condition for the solar simulator was confirmed using a standard cell (BS-500BK). For the IPCE measurements, the devices were tested using a monochromatic Xenon arc light system (Zolix LSP-X150). The microstructure of SWNT films and the cross-sectional structures of the devices were characterized using a SEM (SEM, JEOL JEM-6500F).

\section{References}

1. Chang, L. Y. et al. Low-temperature solution-processed solar cells based on PbS colloidal quantum dot/CdS heterojunctions. Nano Lett. 13, 994-999 (2013).

2. Strein, E. et al. Charge generation and energy transfer in hybrid polymer/ infrared quantum dot solar cells. Energy Environ. Sci. 6, 769-775 (2013).

3. Semonin, O. E. et al. Peak external photocurrent quantum efficiency exceeding $100 \%$ via MEG in a quantum dot solar cell. Science 334, 1530-1533 (2011).

4. Brittman, S., Gao, H. W., Garnett, E. C. \& Yang, P. D. Absorption of light in a single-nanowire silicon solar cell decorated with an octahedral silver nanocrystal. Nano Lett. 11, 5189-5195 (2011).

5. Kempa, T. J., Day, R. W., Kim, S. K., Park, H. G. \& Lieber, C. M. Semiconductor nanowires: a platform for exploring limits and concepts for nano-enabled solar cells. Energy Environ. Sci. 6, 719-733 (2013).

6. Kim, S. K. et al. Tuning light absorption in core/shell silicon nanowire photovoltaic devices through morphological design. Nano Lett. 12, 4971-4976 (2012).

7. Bronstein, N. D. et al. Luminescent solar concentration with semiconductor nanorods and transfer-printed micro-silicon solar cells. ACS Nano 8, 44-53 (2014).

8. Appenzeller, J. et al. Field-modulated carrier transport in carbon nanotube transistors. Phys. Rev. Lett. 89, 126801 (2002).

9. Li, Y. F., Kaneko, T., Kong, J. \& Hatakeyama, R. Photoswitching in azafullerene encapsulated single-walled carbon nanotube FET devices. J. Am. Chem. Soc. 131, 3412-3413 (2009).

10. Miyauchi, Y. et al. Brightening of excitons in carbon nanotubes on dimensionality modification. Nat. Photonics 7, 715-719 (2013).

11. Miyauchi, Y. Photoluminescence studies on exciton photophysics in carbon nanotubes. J. Mater. Chem. C 1, 6499-6521 (2013).

12. Chen, C. W., Lee, M. H. \& Clark, S. J. Band gap modification of single-walled carbon nanotube and boron nitride nanotube under a transverse electric field. Nanotechnology 15, 1837-1843 (2004).

13. Durkop, T., Getty, S. A., Cobas, E. \& Fuhrer, M. S. Extraordinary mobility in semiconducting carbon nanotubes. Nano Lett. 4, 35-39 (2004).

14. Kanungo, M., Lu, H., Malliaras, G. G. \& Blanchet, G. B. Suppression of metallic conductivity of single-walled carbon nanotubes by cycloaddition reactions. Science 323, 234-237 (2009).
15. Wang, F. et al. Fabrication of single-walled carbon nanotube/Si heterojunction solar cells with high photovoltaic performance. ACS Photonics 1, 360-364 (2014).

16. Rowell, M. W. et al. Organic solar cells with carbon nanotube network electrodes. Appl. Phys. Lett. 88, 233506 (2006).

17. Kongkanand, A., Dominguez, R. M. \& Kamat, P. V. Single wall carbon nanotube scaffolds for photoelectrochemical solar cells. capture and transport of photogenerated electrons. Nano Lett. 7, 676-680 (2007).

18. Chen, J. K. et al. A flexible carbon counter electrode for dye-sensitized solar cells. Carbon 47, 2704-2708 (2009).

19. Li, X. et al. Controlled doping of carbon nanotubes with metallocenes for application in hybrid carbon nanotube/Si solar cells. Nano Lett. 14, 3388-3394 (2014).

20. Wang, F., Kozawa, D., Miyauchi, Y., Hiraoka, K., Mouri, S. \& Matsuda, K. Enhancement mechanism of the photovoltaic conversion efficiency of single-walled carbon nanotube/Si solar cells by $\mathrm{HNO}_{3}$ doping. Appl. Phys. Express 6, 102301 (2013).

21. Avouris, P., Chen, Z. H. \& Perebeinos, V. Carbon-based electronics. Nat. Nanotechnol. 2, 605-615 (2007).

22. Sun, D. M. et al. Flexible high-performance carbon nanotube integrated circuits. Nat. Nanotechnol. 6, 156-161 (2011).

23. Tiedje, T., Yablonovitch, E., Cody, G. D. \& Brooks, B. G. Limiting efficiency of silicon solar-cells. IEEE Trans. Electron. Dev. ED-31, 711-716 (1984).

24. Brown, P. R. et al. Improved current extraction from $\mathrm{ZnO} / \mathrm{PbS}$ quantum dot heterojunction photovoltaics using a $\mathrm{MoO}_{3}$ interfacial layer. Nano Lett. 11, 2955-2961 (2011).

25. Kroger, M. et al. Role of the deep-lying electronic states of $\mathrm{MoO}_{3}$ in the enhancement of hole-injection in organic thin films. Appl. Phys. Lett. 95, 123301 (2009).

26. Kozawa, D., Hiraoka, K., Miyauchi, Y., Mouri, S. \& Matsuda, K. Analysis of the photovoltaic properties of single-walled carbon nanotube/silicon heterojunction solar cells. Appl. Phys. Express 5, 042304 (2012).

27. Jung, Y., Li, X. K., Rajan, N. K., Tayor, A. D. \& Reed, M. A. Record high efficiency single-walled carbon nanotube/silicon p-n junction solar cells. Nano Lett. 13, 95-99 (2013).

28. Dukovic, G. et al. Structural dependence of excitonic optical transitions and band-gap energies in carbon nanotubes. Nano Lett. 5, 2314-2318 (2005).

29. Liu, P. et al. Measuring the work function of carbon nanotubes with thermionic method. Nano Lett. 8, 647-651 (2008).

30. Wildoer, J. W. G., Venema, L. C., Rinzler, A. G., Smalley, R. E. \& Dekker, C. Electronic structure of atomically resolved carbon nanotubes. Nature 391, 59-62 (1998)

31. Meyer, J. et al. Transition metal oxides for organic electronics: energetics, device physics and applications. Adv. Mater. 24, 5408-5427 (2012).

32. Irwin, M. D., Buchholz, B., Hains, A. W., Chang, R. P. H. \& Marks, T. J. p-Type semiconducting nickel oxide as an efficiency-enhancing anode interfacial layer in polymer bulk-heterojunction solar cells. Proc. Natl Acad. Sci. USA 105, 2783-2787 (2008).

33. Dimitrov, V. \& Sakka, S. Electronic oxide polarizability and optical basicity of simple oxides. J. Appl. Phys. 79, 1736-1740 (1996).

34. Hellstrom, S. L. et al. Strong and stable doping of carbon nanotubes and graphene by $\mathrm{MoO}_{\mathrm{x}}$ for transparent electrodes. Nano Lett. 12, 3574-3580 (2012)

35. Oh, J., Yuan, H-C. \& Branz, H. M. An 18.2\%-efficient black-silicon solar cell achieved through control of carrier recombination in nanostructures. Nat. Nanotechnol. 7, 743-748 (2012).

36. Agostinelli, G. et al. Very low surface recombination velocities on p-type silicon wafers passivated with a dielectric with fixed negative charge. Sol. Energ. Mat. Sol. C 90, 3438-3443 (2006).

37. Koide, N., Islam, A., Chiba, Y. \& Han, L. Improvement of efficiency of dye-sensitized solar cells based on analysis of equivalent circuit. J. Photochem Photobiol. A 182, 296-305 (2006).

38. Moisala, A. et al. Single-walled carbon nanotube synthesis using ferrocene and iron pentacarbonyl in a laminar flow reactor. Chem. Eng. Sci. 61, 4393-4402 (2006).

39. Sun, D. M. et al. Mouldable all-carbon integrated circuits. Nat. Commun. 4, 2302 (2013).

\section{Acknowledgements}

We are grateful to M. Endo, A. Wakamiya and Y. Murata for their help with the $n$-SWNT/p-Si fabrication instruments supply. Y.M. was financially supported by the Precursory Research for Embryonic Science and Technology (PRESTO), Japan Science and Technology (JST). This study was supported by a Grant-in-Aid for Scientific Research from the Japan Society for the Promotion of Science (JSPS) (Grant Nos. $22740195,23340085,24681031$, and 40311435), the Yazaki Memorial Foundation for Science and Technology, the Nippon Sheet Glass Foundation for Materials Science and Engineering, and The Canon Foundation.

\section{Author contributions}

K.M. directed the study and obtained financial support. F.W. proposed the idea and the strategy for the experimental design and did the experiments. Y.O synthesized the 
single-carbon nanotube samples. K.M., F.W., D.K., S.M. and K.H. were responsible for the data analysis. F.W., D.K., Y.M., K.H., S.M., Y.O. and K.M. discussed the results and contributed to writing the manuscript.

\section{Additional information}

Supplementary Information accompanies this paper at http://www.nature.com/ naturecommunications
Competing financial interests: The authors declare no competing financial interests.

Reprints and permission information is available online at http://npg.nature.com/ reprintsandpermissions/

How to cite this article: Wang, F. et al. Considerably improved photovoltaic performance of carbon nanotube-based solar cells using metal oxide layers. Nat. Commun. 6:6305 doi: 10.1038/ncomms7305 (2015). 